\title{
A MOTIVAÇÃO EMPREENDEDORA DOS JOVENS E SUA RELEVÂNCIA PARA O DESENVOLVIMENTO SOCIOECONÔMICO EM SÃO LUÍS
}

\author{
THE ENTREPRENEURIAL MOTIVATION OF YOUNG PEOPLE AND THEIR RELEVANCE FOR \\ SOCIOECONOMIC DEVELOPMENT IN SÃO LUÍS
}

Recebido em 03.12.2020 Aprovado em 03.06.2021

Avaliado pelo sistema double blind review DOI: https://doi.org/10.32888/cge.v9i1.47468

\author{
Valkiria Silva Raposo \\ valkiria.sraposo@gmail.com \\ GPADS/Universidade CEUMA- São Luís/Maranhão, Brasil \\ https://orcid.org/0000-0003-3007-9576 \\ Willian Naldo Coelho Oliveira \\ willian95875@ceuma.com.br \\ GPADS/Universidade CEUMA- São Luís/Maranhão, Brasil \\ https://orcid.org/0000-0003-4879-2863 \\ Paulo Roberto Campelo Fonseca e Fonseca \\ fonseca.e.fonseca@hotmail.com \\ GPADS/Universidade CEUMA-São Luís/Maranhão, Brasil \\ https://orcid.org/0000-0001-9106-2781
}

\section{Resumo}

O artigo possui como problema: qual a motivação empreendedora dos jovens empresários ludovicenses. Sendo assim, o objetivo foi de levantar as principais motivações que levaram os jovens empresários ludovicenses a empreender. Para obtenção dos dados, foi aplicado um formulário eletrônico em uma IES entre jovens universitários. Quanto à abordagem a pesquisa foi quantitativa, haja vista ter se analisado de forma quantitativa o nível de concordância e discordância com sete variáveis apontadas pela literatura como as principais motivações empreendedoras junto a jovens empresários maranhenses. O resultado da pesquisa apontou que a variável que mais motiva os jovens a empreenderem dentre as sete analisadas foi alcançar a independência financeira.

Palavras-chave: Perfil de empreendedores. Motivações. Empreendedor jovem.

\begin{abstract}
The article has as a problem: what is the entrepreneurial motivation of young Ludovicense entrepreneurs. Thus, the objective was to raise the main motivations that led young entrepreneurs from Ludovic to undertake. To obtain the data, an electronic form was applied at an HEI among young university students. As for the approach, the research was quantitative, considering that the level of agreement and disagreement was analyzed quantitatively with seven variables identified in the literature as the main entrepreneurial motivations with young entrepreneurs from Maranhão. The result of the research pointed out that the variable that most motivates young people to undertake among the seven analyzed was to achieve financial independence.
\end{abstract}

Keywords: Entrepreneurs profile. Motivations. Young entrepreneur. 


\section{Introdução}

É nítido a contribuição das empresas para o desenvolvimento na economia em todos os âmbitos, seja no país, estado e município. Sendo assim, geradoras de oportunidades de emprego para aqueles que se encontram desempregados. Entretanto, é importante que se compreenda que uma empresa para que ela se inicie necessitará de muito esforço e dedicação daqueles que a compõem. Ou seja, entende-se que os empreendedores desempenham um papel fundamental, no sentido economicamente, na região que se alojam. O empreendedorismo tem atuado de forma significativa na economia e uma porcentagem desses empreendimentos são administrados por jovens que anseiam mudar de vida e alcançar um outro patamar social e econômico.

Entretanto, vale ressaltar que as instituições federais, estaduais e municipais devem exercer o seu papel também, e qual seria? Seria a iniciativa de motivar os jovens a investirem em um empreendimento, pois além de ser algo positivo para o jovem abrangerá não somente eles, mas a sociedade impactando no setor econômico. Diante do exposto, este artigo possui como problemática: qual a motivação empreendedora dos jovens empresários ludovicenses. Sendo assim, a partir desta problemática, este artigo possui como objetivo levantar as principais motivações que levaram os jovens empresários ludovicenses a empreender. Partindo deste princípio, este artigo, tem por finalidade fazer um estudo acerca da motivação empreendedora de jovens e a relevância desse empreendedorismo para o desenvolvimento socioeconômico na cidade de São Luís-Maranhão. Tendo em vista que os jovens têm participado cada vez mais na do engajamento do setor economia.

Para buscar uma resposta consistente quanto qual tem sido a motivação empreendedora dos jovens e sua relevância economicamente na cidade de São Luís, este trabalho está estruturado em três capítulos. O primeiro destina-se quanto ao conceito do que empreendedorismo e sua importância segundo autores, pois se visa mostrar a percepção de teóricos quanto ao conceito da palavra supracitada. Na segunda parte, será destinada qual tem sido a motivação que tem levado os jovens a serem empreendedores. E por fim, no último capítulo será abordado sobre a participação dos empreendedores na economia da cidade de São Luís. Considerando-se a relevância do tema abordado por este trabalho, o presente artigo tem como problema de pesquisa: entender quais as razões para os jovens empreenderem? Tal questionamento há de requerer tanto, uma revisão bibliográfica quanto, a utilização de mecanismos de observação ou coleta de informações capazes de permitirem que, a temática investigada atinja o objetivo geral da pesquisa.

\section{Referencial Teórico}

Para que o presente artigo atinja seus propósitos, é necessário que se faça uma contextualização acerca das teorias e artigos existentes cujo proposito será o de dar consistência técnica-cientifica a este trabalho. Neste sentido, é requerida uma abordagem aos seguintes temas: Motivação Empreendedora; Empreendedorismo e Desenvolvimento Socioeconômico; e Educação Empreendedora que, entende-se, ser o caminho para a análise do problema suscitado neste artigo.

\section{Motivação Empreendedora}

Nos últimos anos, ganharam força, nas literaturas internacional e nacional, investigações acerca dos motivos que levam os indivíduos à atividade empreendedora. No Brasil, a pesquisa vem sendo conduzida, desde o ano 2000, pelo Instituto Brasileiro de Qualidade e Produtividade - IBQP, em parceria com o Centro de Empreendedorismo 
e Novos Negócios da Fundação Getúlio Vargas, contando com o apoio do SEBRAE e de outras entidades (VALE, CORREAA; REIS, 2014, p. 313). O empreendedorismo pode ser compreendido como a arte de fazer acontecer com criatividade e motivação. Consiste no prazer de realizar com sinergismo e inovação qualquer projeto pessoal ou organizacional, em desafio permanente às oportunidades e riscos. É assumir um comportamento proativo diante de questões que precisam ser resolvidas (IMAGINÁRIO, 2017, p. 15).

A motivação é um processo psicológico básico despertado por necessidades, afetos, valores, metas e expectativas, que estimulam o indivíduo a agir de maneira persistente para atingir objetivos (GONDIM; SILVA, 2013, p.24). O estudo do empreendedorismo é um processo que começa com a decisão de se tornar empreendedor, seguido pelo caminho de selecionar a oportunidade certa, escolher as pessoas certas em prol do mesmo objetivo, construir o modelo de negócio e escolher os recursos para financiar o mesmo. (BLUMENTHAL,2013, p. 34).

As empresas são um dos fatores mais importantes para o progresso econômico e social de uma localidade ou região, sendo hoje em dia uma das principais soluções para o problema do desemprego. É difícil imaginar-se uma sociedade avançada sem uma florescente atividade empresarial, onde os empresários como agentes empreendedores desempenham um papel fundamental (CARVALHO; GONZÁLEZ, 2006, p. 43). Aspectos subjetivos, como capacidade de inovar e lidar com a incerteza são igualmente relevantes. Ao inovar, o empreendedor incorpora novos conhecimentos a produtos, processos, mercados e organizações. Sua percepção de maior controle dos resultados de suas ações o torna mais hábil a lidar com ambientes instáveis (LOIOLA et al, 2016, p. 24).

Conforme afirma Drucker (1987, p. 15) a inovação está na essência do empreendedor, onde cada um reage de forma diferente às mudanças e transformam como uma oportunidade de negócio, motivado pelo desejo da criação de um negócio ou serviço inovador. Tendo em vista que o mercado proporciona oportunidades relevantes para empreender, contudo é necessário monitorar, por exemplo, modificações do meio ambiente e analisar os influenciadores do comportamento do consumidor como a população, emprego, faixa etária, grau de instrução, renda per capita e os produtos consumidos. Diante disso, compreende-se que o empreendedor busca novas possibilidades e oportunidades de negócio, criando novos serviços e produtos com métodos de produção inovadores e explorando a comercialização para novos nichos de mercados. Muito se tem estudado e discutido no mundo acadêmico, sobretudo nas últimas décadas em relação a relevância do empreendedorismo. O entendimento de como o empreendedorismo acontece e como pode ser lecionado mostra-se importante para os indivíduos, assim aumentando suas chances de identificar e explorar as oportunidades do mercado. A compreensão de como o empreendedorismo acontece e como pode ser ensinado mostra-se relevante para que os indivíduos possam aumentar suas chances de se identificar com o negócio, bem como para a expansão de uma cultura favorável ao empreendedorismo (NECK; GREENE, 2011, p. 55).

O empreendedorismo pode ocorrer de duas maneiras: por necessidade ou por oportunidade. Verifica-se que o empreendedorismo de necessidade é mais comum em países em desenvolvimento e isso contribui para as altas estatísticas de mortalidade das empresas que, sem planejamento e respaldo necessários logo fracassam em decorrência principalmente da falta de conhecimento (CUNHA; SILVA; YAMAGUCHI, 2012, p. 171). Já os empreendedores por oportunidade, por sua vez, buscam criar empresas motivados pela percepção de uma oportunidade potencial de mercado, e convencidos de que poderão ser bem-sucedidos em seu empreendimento. Podem ainda ocorrer ambos os casos, aliando-se a componente de oportunidade a uma necessidade e vice-versa. Portanto, apesar de conceptualmente distintas, por vezes coexistem (HUMBERT, 2010, p. 177).

Vale e Guimarães (2010, p. 330) referem ainda a importância de contatos prévios à criação da empresa e dos "ambientes empresariais". Estabelecer contatos com pessoas numa situação idêntica pode ser um fator de sucesso dos empreendimentos. Outros fatores de sucesso, segundo as autoras, são: o nível elevado de escolaridade, experiências prévias, competências em gestão e empreender por oportunidade. No ver destas autoras o empreendedorismo de necessidade tem menor probabilidade de sucesso. Naia (2009, p. 14) acrescenta outros fatores de sucesso como o desenvolvimento de negócios no contexto familiar, formação inicial e continuada e contatos profissionais. 
Entretanto, existe um fator importante, que algumas vezes pode ser confundido, é que a palavra inovação não se atribui apenas a amplas e boas ideias, ou seja, inovar não se refere somente a invenções, inovação diz respeito a ideias que tenham repercussão e impactos no mercado. Podemos dizer que o que diferencia o empreendedor do inventor, é a habilidade de modificar a invenção em um empreendimento, por meio da inovação, introdução, inserção institucionalização e efeitos em grandes escalas de produção, conquistando assim novos adeptos e preservando os já existentes, ou seja, desenvolvendo a passagem do projeto de criação à repercussão social e económica (NAIA, 2009, p. 11).

A motivação para empreender está envolvida com percepções ligada a fatores como 'Risco x Recompensa'. A maioria dos autores especialistas em empreendedorismo trata a motivação para empreender com base no comportamento do empreendedor frente à sua percepção da relação recompensa, risco e sucesso, utilizando como metodologia suas observações pessoais ou com informações obtidas em estudos estruturados com base na impressão destes empreendedores (RIBAS, 2011, p. 3).

A tomada de decisão para gerir um empreendimento pode ocorrer por uma eventualidade, devido a afinidades pessoais, fatores externos, ambientais e sociais, ou devido ao conjunto de todos esses fatores. O processo empreendedor se inicia através de um evento gerador desses fatores, que possibilita o início de um negócio. A atividade empreendedora envolve a descoberta e exploração de novas oportunidades, onde o conceito de oportunidade empreendedora abrange os aspetos externos de origem ambiental e ou institucional que facilitam o empreendedorismo, e a capacidade que algumas pessoas têm para encontrar a melhor combinação ou articulação entre os recursos (PINHO; THOMPSON, 2016, p. 167).

Valliere (2010, p. 98), quanto à motivação do empreendedorismo por oportunidade ou por necessidade. O autor corrobora que a motivação é por oportunidade e não por necessidade, os empresários podem escolher a melhor opção, ou seja, o conhecimento em determinada atividade empresarial, acaba tornando mais acessível o empreendimento. Contudo o empreendedor necessariamente precisa estar hábil para tal função, que exige não só conhecimento na área que se deseja empreender mais também planejamento, objetivos claros, estratégias para identificar as oportunidades nos locais mais improváveis. No entanto montar um projeto e colocar em prática, exige altos riscos, que nem sempre o empreendedor está disposto a correr, lidar com as frustações, exige uma certa tolerância para seguir diante a tantos desafios, e continuar motivado (BOZZO, 2019, p. 282).

Para um empreendedor, o fracasso é considerado um resultado como qualquer outro. Com o passar do tempo e o aprofundamento nos estudos, percebeu-se que o cenário está diferente. Opiniões outrora fundamentadas, foram consumidas pela evolução do mercado e a tecnologia empregada para novos produtos que se faz necessário adaptação desse empreendedor para alcançar seus objetivos a fim de obter sucesso nos negócios buscando melhorias aprimoramentos, mantendo-se motivado em prol de alcançar seus objetivos e metas (FIALHO et al, 2018, p. 155).

\section{Empreendedorismo e Desenvolvimento Socioeconômico}

Fiorentin et al. (2018, p.2) preconizam que “o empreendedorismo tem uma relação direta com a criatividade e o poder de inovação do ser humano, pois com a evolução da sociedade os indivíduos tendem a se reinventarem e aprender uma nova maneira de desenvolve-se". Isto nos levar a refletir que as pessoas vivem em busca de algo que os motiva, levando-os a questionar, buscar novas oportunidade, passar por experiências ainda não exploradas, afim de retém conhecimento.

Desta forma o empreendedorismo é um elemento impulsionador do desenvolvimento econômico e social de uma região, o qual geralmente se assume que empreendedorismo se encontra sempre e em qualquer lugar associado ao processo econômico, pois além de trazer esse retorno financeiro, aquele que é considerado empreendedor acaba que por incentivar outros a terem o mesmo desejo de investir em uma empresa que seja totalmente sua, visto que 
todo individuo deseja ser dono do seu próprio negócio e que ao ser dono da sua própria empresa estará tendo algumas compensações (FIORENTIN; JAHN; LEMOS, 2018, p. 3).

Muitos estudos têm sido realizados com o intuito de relacionar a atividade empreendedora e o desenvolvimento econômico. Há de se considerar que o empreendedorismo desempenha um papel importante no desenvolvimento, podendo ser considerado um elemento fundamental para o desenvolvimento econômico dos países. Estudos realizados no Brasil em nível regional observaram que o empreendedorismo foi realmente um fator importante no desenvolvimento econômico daquelas localidades, além de colaborar também com o desenvolvimento humano da população (FELIX; JUNIOR, 2013, p. 105).

O empreendedorismo e sua relação com vários outros temas mais amplos, como o crescimento e desenvolvimento dos países, tem evidenciado um campo de pesquisa caracterizado pela sua interdisciplinaridade e complexidade, mas também pela amplitude de suas possibilidades de desenvolvimento científico. A relação entre empreendedorismo e crescimento econômico, por exemplo, parece clara, principalmente quando a discussão está centrada nas diferenças de impacto dessa relação entre os países (FONTENELE, 2010, p. 1096).

Com a criação e difusão de indicadores macroeconômicos como o Global Entrepreneurship Monitor [GEM] e o Growth Competitiveness Index [GCI], tornou-se possível aprimorar a compreensão da relação do empreendedorismo com o crescimento econômico. O GEM, por exemplo, adota postura mais abrangente e considera a contribuição de todo tipo de negócio no crescimento dos países, visto que a pesquisa parte da premissa de que o crescimento econômico resulta da ação de dois processos distintos, porém complementares: as atividades de inserção e intercâmbio no comércio internacional, promovidas por empresas estabelecidas de grande porte, que geram demandas internas por novos produtos e serviços, e as atividades diretamente relacionadas com o processo empreendedor e que são responsáveis pela criação e crescimento de novas empresas (FONTENELE, 2010, p. 1096).

O empreendedorismo tem sido apontado como vetor de geração de emprego e renda. Por terem impactos diferentes, alguns estudos na literatura procuram avaliar o papel do empreendedorismo, quando motivado por oportunidade e por necessidade no desenvolvimento econômico dos países. O empreendedorismo por oportunidade tem sido visto como de melhor resultado para o desenvolvimento das nações, uma vez que existe uma alta relação com a inovação na ação empreendedora (ROCHA, 2014, p. 32).

Figura 1: Gráfico GEM - Empreendedorismo por oportunidade e necessidade como proporção (em\%) da taxa de empreendedorismo inicial- Brasil - 2002:2017

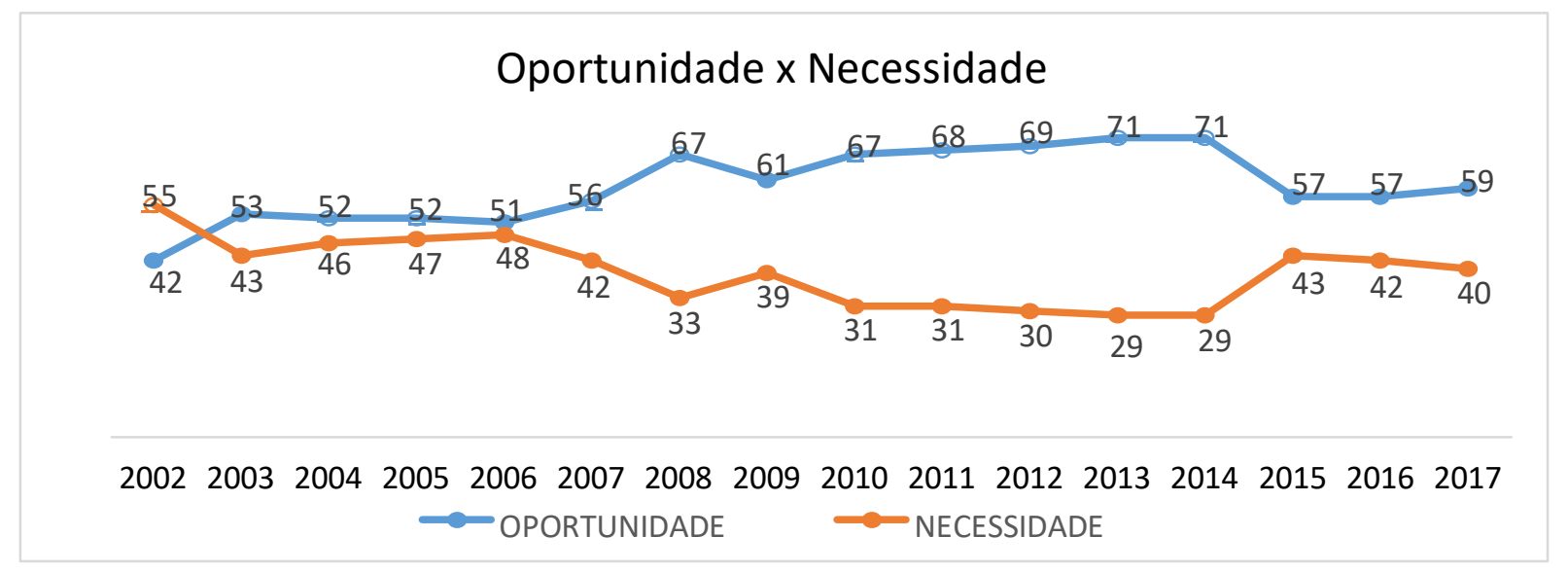

Fonte: Adaptado do GEM (2017, p.10)

O nível de desenvolvimento econômico de um país é um fator importante na explicação da sua atividade empreendedora. Ainda que exista vários aspectos que intervêm no desenvolvimento e crescimento da economia no país; o empreendedor tem uma função expressiva nesse contexto. $O$ cenário atual do mercado pode ser ISSN 2318-9231 CGE | Rio de Janeiro | v. 9 | n. 1 | jan. - abr. 202150 
designado como era do empreendedorismo, visto que os empreendedores estão criando áreas comercias com menores distancias e gerando riqueza, além de criar maior empregabilidade na sociedade. (TAVARES; MOURA; SILVA, 2014, p. 17).

\section{Educação Empreendedora}

O capital humano de um empreendedor pode dispor de conhecimento, habilidades e atitudes para solucionar problemas, os quais são transferíveis para várias situações distintas. Através da educação é possível despertar o espirito empreendedor nos jovens. Embora a educação tenha uma influência positiva sobre a probabilidade de uma pessoa descobrir novas oportunidades, ela não determina necessariamente que essa pessoa crie um negócio e tenha sucesso no empreendimento. Sua importância se reflete não só no nível educacional obtido, mas também no fato de que continua a desempenhar um grande papel ao auxiliar os empreendedores a lidar com os problemas que enfrentam (HISRICH; PETERS; SHEPHERD, 2014, p. 12).

A educação para a cidadania e empreendedorismo constitui-se nessa ótica como uma dimensão estratégica para um novo desenvolvimento na medida em que permita formar cidadãos reflexivos e empáticos, capazes de reconstruir cooperativamente (e não somente competitivamente) ideias e propostas em diferentes contextos e situações, produzindo desse modo um "conhecimento sociável, ou seja, um conhecimento que é significativo porque possibilita novas formas de envolvimento no mundo (ALBUQUERQUE; FERREIRA; BRITES, 2016, p. 1038)

A importância da educação empreendedora para o desenvolvimento de uma nação tem sido reconhecida, não apenas no Brasil, mas em diversos países do mundo, tendo sido colocada como prioritária nas agendas e debates políticos, econômicos e acadêmicos, incluindo os mais altos níveis de discussão das Nações Unidas. Conferências promovidas pelo órgão internacional da ONU responsável pela economia e pelo desenvolvimento apontam quatro áreas-chave para a educação empreendedora: a) incorporação do empreendedorismo na educação e treinamento, b) o desenvolvimento curricular, c) o desenvolvimento do professor e d) o engajamento com o setor privado (SCHAEFER; MINELLO, 2016, p. 63).

Além disso, o desenvolvimento e implementação de programas de educação empreendedora seguem as recomendações da Unesco para a educação do século XXI, que são aprender a conhecer, aprender a fazer, aprender a conviver e aprender a ser. Além dessas dimensões, a Unesco recomenda outros aspectos da moderna educação relacionados ao empreendedorismo, a fim de que os estudantes desenvolvam a capacidade de inovar, reter conhecimento, desenvolver projetos próprios e lidar com as mudanças (LOPES; TEIXEIRA, 2010, p. 25).

Pesquisas mostram que a educação empreendedora apresenta um papel primordial no que se refere o desenvolvimento da cultura empreendedora na sociedade moderna. Ademais, o empreendedorismo mostra-se vital para a economia de um país, por auxiliar a instruir e preparar os indivíduos com conhecimentos, habilidades e atitudes necessários para compreender e transformar obstáculos em oportunidades e aproveitarem-nas para criar novas empresas, passando então a movimentar a economia do país (DA SILVA; PATRUS, 2017, p. 374).

Ora, o crescimento económico e desenvolvimento social criaram a necessidade de formação específica para atuar nesta área, impulsionando a criação de cursos que se iniciaram em Escolas de Administração. A primeira iniciativa ocorreu em 1947, nos Estados Unidos, com o intuito de qualificar ex-combatentes da Segunda Guerra Mundial para o mercado de trabalho. Mas, somente na década de setenta do século passado, as universidades e escolas de negócios começaram a desenvolver programas para a formação de empreendedores, sendo que a expansão definitiva deste ensino se deu na década de oitenta (PARREIRA et al, 2016, p. 267).

A educação empreendedora é a mais recente conquista da área de empreendedorismo, e pode-se afirmar que seja uma alternativa para o desenvolvimento social e econômico. No âmbito escolar, as universidades vêm abordando o tema de maneira recorrente. Em boa parte dos cursos já há uma disciplina que trata do assunto seja para aplicação de planos e negócios, seja para desenvolvimento de comportamentos e competências comuns àqueles que 
empreendem. No ensino fundamental e médio, ainda são poucos os casos de escolas que se aprofundam no tema. Porém, a Base Nacional Comum Curricular (BNCC, 2018) vem abordando questões como protagonismo e autonomia com regularidade (CAÑETE; CARDOSO, 2019, p.154).

O objetivo da educação empreendedora é fazer com que o educando seja autônomo, que possa fazer suas próprias escolhas, de modo a fortalecer seu projeto de vida, tornando-se um sujeito ativo na construção do desenvolvimento social. Por tratar-se de um novo tema na educação brasileira, o empreendedorismo gera uma certa polêmica quando a discussão é a sua inclusão obrigatória no currículo escolar. Apesar de alguns educadores considerarem que o empreendedorismo não pode ser ensinado, pelo fato de ser uma qualidade individual ou um dom de cada ser humano, a cada dia, cresce o número de escolas brasileiras que adotaram o empreendedorismo como disciplina eletiva. Na realidade, essas escolas estão introduzindo seus alunos no mundo corporativo e oferecendo atividades acadêmicas voltadas para a formação de empreendedores (NUNES, 2015, p.51).

\section{Procedimentos metodológicos}

Esta pesquisa apresenta o método científico do tipo dedutiva, haja vista que se partiu do geral para o específico, já que se estudou a motivação dos jovens empreendedores de uma Instituição de Ensino Superior - IES privada, a partir das premissas que a literatura de forma geral já apontava como as principais variáveis motivadoras ao empreendedorismo (MARCONI; LAKATOS, 2017, p.90). Quanto à abordagem a pesquisa é quantitativa, já que tabulou-se os dados de forma quantitativa, os quais foram extraídos da aplicação de formulário eletrônico enviado para líderes de turmas de discentes do curso de administração de uma IES privada, a fim de analisar quais são as principais motivações empreendedoras dos jovens empresários maranhenses que estudavam nesta IES privada (VIEIRA; ZOUAIN,2005, p. 4).

O estudo realizado em uma amostra de 61 estudantes universitários pertencentes aos períodos finais do curso de administração, sem distinção de gênero, no município de São Luís - Ma no período de 09 de março a 23 de abril de 2020. Este estudo visou compreender o fenômeno do empreendedorismo e a motivação para inserção neste meio dos jovens empresários e universitários, sendo, portanto, quanto aos seus objetivos de cunho exploratório. (GIL,2017, p.26).

Quanto aos procedimentos para a coleta dos dados, utilizou-se a pesquisa do tipo de levantamento, já que utilizouse questionário eletrônico aplicado em uma IES entre jovens universitários, com o intuito de fazer um levantamento dos contatos dos jovens empresários do maranhão. (GIL, 2017, p.33). A partir desses contatos, buscou-se prospectar os jovens empresários que queriam participar da pesquisa, com os quais foi aplicado formulário eletrônico com sete variáveis estudas, que fora construído com base na literatura do referencial teórico deste artigo. Utilizou-se a escala likert para analisar o nível de concordância, indiferença e discordância dos participantes com as variáveis estudas, bem como com as afirmações relacionadas a cada variável, conforme disposto na tabela 1. A pesquisa também é considerada bibliográfica tendo em vista que se originou de artigos periódicos e livros já publicados formulando assim embasamento teórico para a pesquisa.

Tabela 1 - Variáveis e afirmações utilizadas na pesquisa.

\begin{tabular}{ll}
\hline Variáveis & Afirmações \\
\hline 1. Oportunidade & Possuo facilidade em identificar novas oportunidades de negócios \\
\hline 2. Influência familiar & Quero dar continuidade aos negócios da família \\
\cline { 2 - 2 } & Para dar ocupação aos membros da minha família \\
\hline
\end{tabular}




\section{Possuo familiares influentes na sociedade}

$\begin{array}{ll}\text { 3. Conhecimento do Negócio } & \begin{array}{l}\text { Sou motivado a empreender pois possuo conhecimentos na área do } \\ \text { empreendimento }\end{array}\end{array}$

\begin{tabular}{lll}
\hline 4. Independência Financeira & Tornar-me independente \\
\hline 5. Auto realização/prova de capacidade & Sou motivado a empreender pois desejo ter um negócio próprio \\
\hline $\begin{array}{l}\text { 6. Ambiente externo/mercado de } \\
\text { trabalho }\end{array}$ & Sou motivado a empreender pois possuo capital disponível \\
\hline 7. Insatisfação profissional & Sou motivado a empreender por estar insatisfeito com o emprego
\end{tabular}

Fonte: Do Autor (2020)

\section{Apresentação e análise dos resultados}

A figura do empreendedor está cada vez mais evidente no cenário mundial e neste processo, é de suma importância observar o perfil de quem busca empreender. Diante isto, o presente estudo apresenta como resultado o diagnóstico acerca do perfil de gênero motivado a criar o seu próprio negócio. Resultado que pode estar embasado nas influências feministas de empoderamento em plena evidência e crescente adesão para aquisição de maior independência financeira e reconhecimento por todas as camadas empresariais. Amostra dos participantes em termos, por exemplo, gênero foram 65,6\% mulheres e 34,4 homens com idade distintas de 18 a 24 anos total de $52,50 \%$ dos respondentes, a pesquisa obteve um número maior de resposta no $8^{\circ}$ período do curso de administração um total de $47,5 \%$.

Figura 2: Tabela - Amostra dados pessoais dos respondentes

\begin{tabular}{|c|c|c|c|c|}
\hline \multicolumn{5}{|l|}{ Idade } \\
\hline $\begin{array}{l}18 \text { a } 24 \text { anos } \\
(52,5 \%)\end{array}$ & & $\begin{array}{l}25 \text { a } 34 \text { anos } \\
(31,10 \%)\end{array}$ & $\begin{array}{l}35 \text { a } 44 \text { anos } \\
(13,10 \%)\end{array}$ & $\begin{array}{l}45 \text { a } 54 \text { anos } \\
(3,30 \%)\end{array}$ \\
\hline \multicolumn{2}{|l|}{ Gênero } & Feminino $(65,60 \%)$ & $\begin{array}{l}\text { Masculino } \\
(34,40 \%)\end{array}$ & \\
\hline \multicolumn{5}{|c|}{ Período do curso } \\
\hline $3^{\circ}$ & $4^{\circ}$ & $6^{\circ}$ & $7^{\circ}$ & $8^{\circ}$ \\
\hline$(4,9 \%)$ & $(14,8 \%)$ & $(9,8 \%) \quad(8,2 \%)$ & $(14,8 \%)$ & $(47,5 \%)$ \\
\hline \multicolumn{2}{|l|}{ Turno } & Matutino $(21,3 \%) \quad \mathrm{Ve}$ & ertino $(14,8 \%)$ & Noturno $(63,9 \%)$ \\
\hline \multicolumn{2}{|c|}{$\begin{array}{l}\text { Trabalha na área do curso } \\
\text { de administração }\end{array}$} & \multicolumn{3}{|c|}{ Não $(42,60 \%)$} \\
\hline
\end{tabular}

Fonte: Do Autor (2020)

Fatores motivadores do empreendedorismo influenciam decisivamente para a tomada de decisões em todo processo de criação do negócio. Estes permeiam desde a identificação da oportunidade perpassando os aspectos familiares, as insatisfações com a carreira ao conhecimento de negócio. Os resultados a seguir foram obtidos através de uma análise fatorial. 
Figura 3: Tabela - Amostra dos participantes de acordo com o fator motivacional (em \%).

\begin{tabular}{|c|c|c|c|c|c|c|}
\hline $\begin{array}{l}\text { FATOR } \\
\text { MOTIVACIONAL }\end{array}$ & AFIRMAÇÕES & 1 & 2 & 3 & 4 & 5 \\
\hline 1. Oportunidade & $\begin{array}{l}\text { Possuo facilidade em identificar } \\
\text { novas oportunidades de negócios }\end{array}$ & $24,6 \%$ & $57,4 \%$ & $13,1 \%$ & $4,90 \%$ & $0,00 \%$ \\
\hline \multirow[t]{3}{*}{$\begin{array}{l}\text { 2. Influência } \\
\text { familiar }\end{array}$} & $\begin{array}{l}\text { Quero dar continuidade aos } \\
\text { negócios da família }\end{array}$ & $16,4 \%$ & $18,0 \%$ & $24,6 \%$ & $24,6 \%$ & $16,4 \%$ \\
\hline & $\begin{array}{l}\text { Para dar ocupação aos membros da } \\
\text { minha família }\end{array}$ & $6,60 \%$ & $23,0 \%$ & $34,4 \%$ & $19,7 \%$ & $16,4 \%$ \\
\hline & $\begin{array}{l}\text { Possuo familiares influentes na } \\
\text { sociedade }\end{array}$ & $1,60 \%$ & $11,5 \%$ & $23,0 \%$ & $32,8 \%$ & $31,10 \%$ \\
\hline TOTAL & & $8,20 \%$ & $17,5 \%$ & $27,3 \%$ & $25,7 \%$ & $21,3 \%$ \\
\hline $\begin{array}{l}\text { 3. Conhecimento } \\
\text { do Negócio }\end{array}$ & $\begin{array}{l}\text { Sou motivado a empreender pois } \\
\text { possuo conhecimentos na área do } \\
\text { empreendimento }\end{array}$ & $11,5 \%$ & $67,2 \%$ & $9,80 \%$ & $9,80 \%$ & $1,60 \%$ \\
\hline
\end{tabular}

\section{Independência Tornar-me independente}

Financeira

$$
62,3 \% \quad 32,8 \% \quad 1,60 \% \quad 3,30 \% \quad 0,00 \%
$$

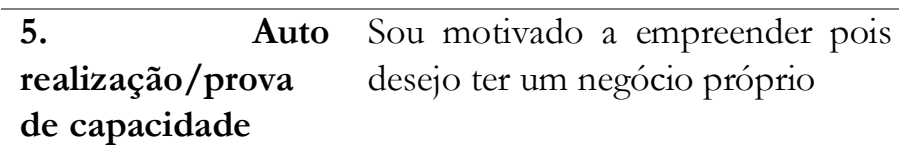

$11,5 \% \quad 31,1 \% \quad 21,3 \% \quad 18,0 \% \quad 18,0 \%$

\begin{tabular}{lllllll}
\hline $\begin{array}{l}\text { 6. Ambiente } \\
\text { externo/mercado } \\
\text { de trabalho }\end{array}$ & $\begin{array}{l}\text { Sou motivado a empreender pois } \\
\text { possuo capital disponível }\end{array}$ & $1,60 \%$ & $19,7 \%$ & $26,2 \%$ & $27,9 \%$ & $24,6 \%$ \\
& & & & & & \\
& & & & & \\
\hline $\begin{array}{l}\text { I. Insatisfação } \\
\text { profissional }\end{array}$ & $\begin{array}{l}\text { Sou motivado a empreender por } \\
\text { estar insatisfeito com o emprego }\end{array}$ & $9,80 \%$ & $23,0 \%$ & $16,4 \%$ & $34,4 \%$ & $16,4 \%$
\end{tabular}

Fonte: Do Autor (2020)

A pesquisa sinalizou a presença de motivações distintas, ao passo das variações apresentadas como opções dispostas ao público. Ao analisar o gráfico 4 se observa os índices de maior percentual dos construtos com maior concordância, na seguinte ordem: (1) Independência Financeira, (2) Oportunidade, (3) Auto realização/prova de capacidade e Conhecimento do Negócio, (4) Insatisfação Profissional, (5) Influência Familiar, (6) Ambiente Externo/Mercado de Trabalho.

Nota-se que, estes construtos se conectam intrinsicamente para que haja uma coerência na "arte" de empreender. Fatores motivacionais isolados não representam a veracidade do processo em sua visão macro, cabendo analisar as particularidades a fim de entender todo o processo, reduzindo de forma significativa o insucesso que acomete expressivamente os empreendedores. 
Figura 4: Gráfico - Empreendedorismo na visão dos jovens empreendedores ludovicenses (em\%) de uma IES.

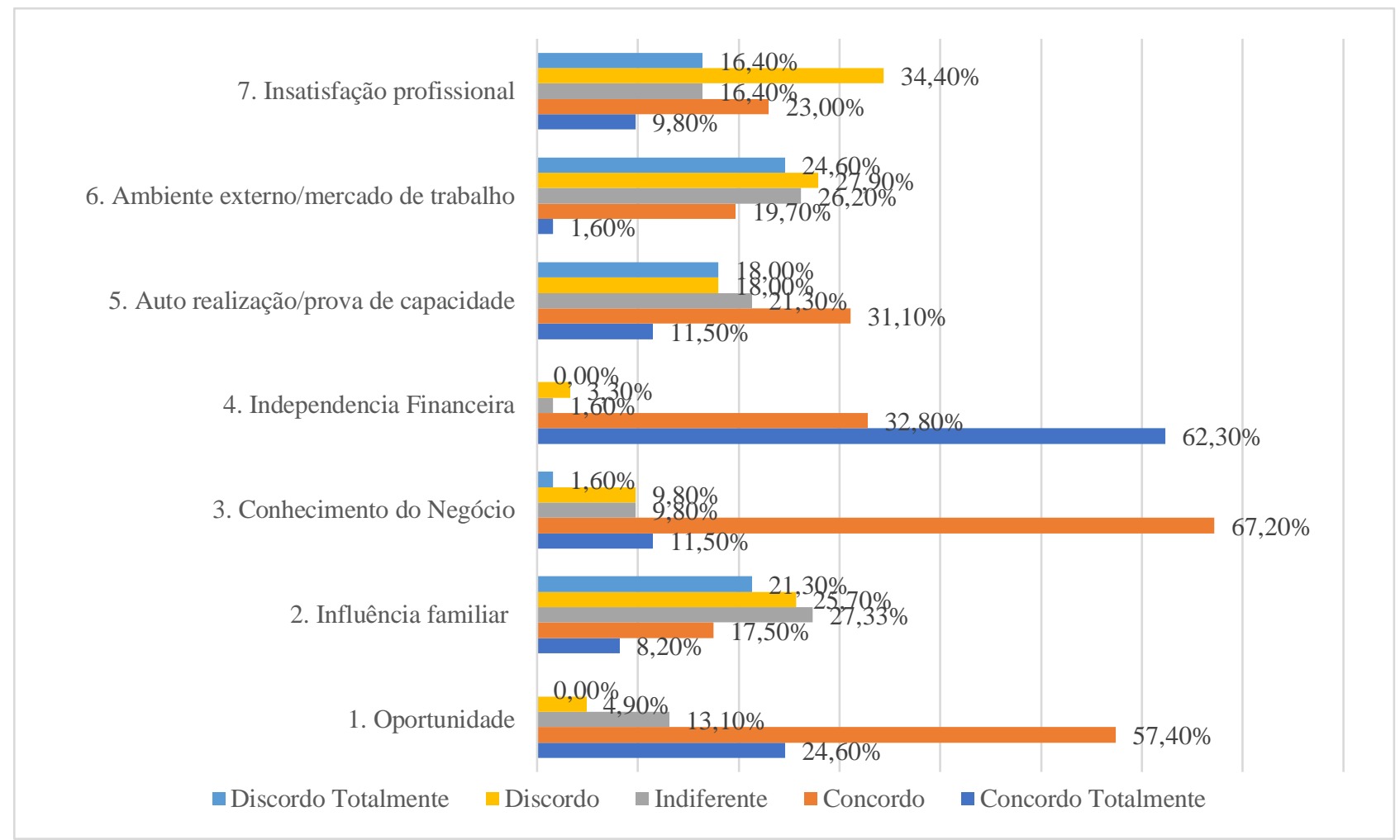

Fonte: Do Autor (2020)

Para também fins de análise, a ordem das motivações múltiplas em percentuais de discordância: (1) Ambiente Externo/Mercado de Trabalho, (2) Influência Familiar, (3) Auto realização/prova de capacidade, (4) Insatisfação Profissional, (5) Conhecimento do Negócio, Independência Financeira e Oportunidade sem manifestações de escore.

Houve também itens nos quais os resultados demonstraram similaridade: Ambiente Externo/Mercado de Trabalho, Auto realização/prova de capacidade, Influência Familiar e Insatisfação Profissional. Estes dados por sua vez, agregados as literaturas já existentes, permitiu para avançar nas problemáticas e resoluções acerca das motivações múltiplas.

As necessidades de mercado abrangem todos os setores, o poder de inovação e identificação de lacunas existentes despertam os olhares mais curiosos, a fim de concretizar esta percepção em Oportunidade. Bem como, as raízes familiares, são fatores ricamente presentes nos lares brasileiros, ocasionando forte Influência Familiar, resultante na tomada de decisão do jovem empreendedor. Ainda há conservadorismo nos lares, nos quais a ideia de estabilidade não adentra o universo empresarial, pautado principalmente no funcionalismo público.

Conhecimento do Negócio é fator essencial para o desenvolvimento do seu projeto. Sobretudo, entender qual o seu nível de entendimento para que os processos sejam dados continuidade. É de suma importância ter este diagnóstico "Até que ponto sei". "Onde preciso buscar mais recursos?", bem como entender o todo, é ter o senso de saber quais seus pontos mais frágeis para realizar os ajustes e que mais impacta os resultados do negócio.

O desejo de ter seu próprio negócio, alcançar a liberdade financeira Independência Financeira é vista como um elemento motivador para o ingresso no mundo empreendedor. Haja vista as oportunidades, as influências familiares e o desejo melhores condições de vida, fazem com que este construto esteja fortemente presente na análise dos porquês de criar o seu próprio negócio. 
Para além do campo econômico, o empreender pode ser vislumbrado como um novo mundo, no qual pode dar novo sentido ao seu eu profissional, a exemplo a Auto realização/prova de capacidade, assim como o construto "Insatisfação Profissional", estes intrinsicamente conectados. Associados ao mercado de trabalho que exige reformulação constante profissional, ou seja, desenvolvimento de novas competências.

O construto com maior concordância observado fora o Independência Financeira, seguido por Oportunidade. Diante os panoramas expostos pela sociedade para o entendimento acerca do porquê empreender e para quê fazêlo, estes pensamentos estão enraizados, o que resulta, em tese, nos motivos pelos quais estes estão em destaque no estudo.

Em outro eixo de análise, o construto no qual apresentou maior divergência, fora Ambiente Externo/Mercado de Trabalho, seguido por Influência Familiar. Assim como os dois supracitados, estes são mais externados visto o cenário que os entrevistados estão inseridos. Trata-se também de abordagens sociais impactantes na tomada de decisão destes estudantes empreendedores.

\section{Considerações finais}

Existem vários fatores que são elementos de interferência na abertura e êxito de um novo empreendimento, dentre eles os construtos de motivação empreendedora tais como pessoais, externos, ambientais, sociais e organizacionais partem de uma concepção pautada na oportunidade, vislumbrando a construção de algo que guie o indivíduo a alçar ares maiores que o sistema tradicional de mercado.

Os adventos das novas concepções empresariais alteraram definitivamente o mercado conservador, a exemplo a startups que motivam cada vez a criação de produtos para atender as mais diversas demandas existentes e olhar para além das quais ainda surgirão.

Este estudo teve por finalidade identificar estes construtos motivadores em jovens de São Luís - Maranhão, feita a análise notou que os fatores motivacionais pessoais e profissionais permeia a visão e tomada de decisões para criação do negócio.

Através deste estudo, se observou que há um movimento acentuado de crescimento do gênero feminino em empreender, integrando maioria da mostra. Este dado corrobora com os novos modelos de sociedade, no qual o empoderamento feminino tomou pose da construção de concepções da era moderna. A mulher como toda carga histórica traz consigo elementos motivadores fortemente enraizados, as multi-habilidades femininas por tanto tempo restritas para o mundo ao lar, são essenciais para o movimento cultural de empreender na atualidade e, ricamente presente nos atributos motivacionais.

De tal modo, os atributos motivacionais podem variar de acordo com as experiências de vida, o gênero, o meio social que o indivíduo está inserido, as relações interpessoais, o grau de formação acadêmica, a localidade, contudo, isto não exclui o que há em comum: a visão de futuro. A literatura aponta os mais diversos cases de sucesso e o quanto são diferentes, porém, todos com características tipicamente comuns que os fazem possuir uma relação de direta e de total sucesso. Ser empreendedor não é tão somente criar algo astronômico, é enxergar o que ainda é oculto para grande maioria e há características que o fazem ser notoriamente diferenciados. Para além da motivação, a persistência é lema para este grupo que busca a criação do livre mercado de oportunidades.

Diante os apontamentos levantados em pesquisa, conclui que os fatores motivacionais são elementos fundamentais para o jovem empreendedor ludovicense. Constatando assim, que se trata de um tema relevante, estratégico para o desenvolvimento da região. 


\section{Referências}

Albuquerque, C. P.; Ferreira, J. S.; Brites, G. (2016). Educação holística para o empreendedorismo: uma estratégia de desenvolvimento integral, de cidadania e cooperação. Revista Brasileira de Educação, v. 21, n. 67, p. 10331056. Disponível em: < http://www.scielo.br/pdf/rbedu/v21n67/1413-2478-rbedu-2167-1033.pdf $>$. Acessado em 19. 11.2019

Block, J. H.; Wagner, M. (2010). Necessity and opportunity entrepreneurs in Germany: characteristics and earning s differentials. Schmalenbach Business Review, v. 62, n. 2, p. $154174 . \quad$ Disponível em: $<$ https://www.researchgate.net/publication/227348568 Necessity and_Opportunity Entrepreneurs in_Germany_Characteristics_and_Earning_s_Differentials >. Acessado em: 05.11.2019

Blumenthal, Y. (2010). Crowdfunding as a financing tool:exploring the extra something. Online], School of Business and Economics, Maastricht Dniversity. Disponível em: < www.academia.edu/2643802/Crowdfunding_As_a_Financing_Tool_Exploring_The_Ext ra_Something_> Acessado em: 03.10.2019

Canever, M. D. et al. (2010). Entrepreneurship in the Rio Grande do Sul, Brazil: the determinants and consequences for the municipal development. Revista de Economia e Sociologia Rural, v. 48, n. 1, p. 85-108. Disponível em: < http://www.scielo.br/pdf/resr/v48n1/05.pdf $>$. Acessado em: 25.10.2019

Carvalho, P. M. R. de; González, L. (2006). Modelo explicativo sobre a intenção empreendedora. Comportamento organizacional e gestão, v. 12, n. 1, p. 43-65. Disponível em: $<$ http://www.scielo.mec.pt/pdf/cog/v12n1/v12n1a04.pdf $>$. Acessado em: 01.10.2019

Chrysostome, E. (2010). The success factors of necessity immigrant entrepreneurs: In search of a model. Thunderbird International Business Review, v. 52, n. 2, p. 137-152. Disponível em: < https://www.deepdyve.com/lp/wiley/the-success-factors-of-necessityimmigrant-entrepreneurs-in-search-of9BUM6pBdnr >. Acessado em: 19.10.2019

Corrêa, V. S.; Vale, G. M. V. A (2018). dinâmica das motivações empreendedoras: uma investigação retrospectiva. Revista Pretexto, v. 14, n. 4, p. 11-28. Disponível em: < http://www.fumec.br/revistas/pretexto/article/view/1441/Artigo\%201 > Acessado em: 02.10.2019

Silva, J. F. da; Patrus, R. (2017). O “bê-á-bá” do ensino em empreendedorismo: uma revisão da literatura sobre os métodos e práticas da educação empreendedora. Revista de Empreendedorismo e Gestão de Pequenas Empresas, v. 6, n. 2, p. 372-401. Disponível em: < http://www.spell.org.br/documentos/ver/46682/o----bea-ba---do-ensino-em-empreendedorismo--uma-revisao-da-literatura-sobre-os-metodos-epraticas-da-educacaoempreendedora $>$. Acessado em 27.11.2019

Rocha, E. L. de C. (2014). Oportunidade ou necessidade? Um estudo do impacto do empreendedorismo no desenvolvimento econômico. Revista Gestão em Análise, v.3,n.1/2,p.3146. Disponível em:

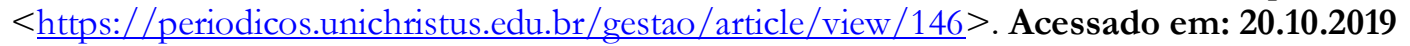

Félix, R. D. C.; Júnior, M. F. F. (2013). Empreendedorismo e desenvolvimento nos municípios paranaenses-uma análise dos indicadores. Revista Brasileira de Planejamento e Desenvolvimento, v. 2, n. 2, p. $104-117$. Disponível em: $<$ https://periodicos.utfpr.edu.br/rbpd/article/download/3080/2098 $>$. Acessado em

27.11 .2019

Fialho, C. B. et al. (2018). MOTIVAÇÃO PARA EMPREENDER EM CENÁRIO DE CRISE ECONÔMICA: UM ESTUDO COM NOVOS EMPREENDEDORES. Revista Livre de Sustentabilidade e Empreendedorismo, v. 3, n. 1, p. 148-175. Disponível em: < http://periodicos.uem.br/ojs/index.php/CadAdm/article/view/37964/751375139778>. 
Acessado em: 01.11.2019

Fiorentin, R. A. J.; Jahn, R.; Lemos, T. (2018). DO EMPREENDEDORISMO AO DESENVOLVIMENTO SOCIOECONÔMICO. Seminário de Ciências Sociais Aplicadas, v. 6, n. 6. Disponível em: < http://periodicos.unesc.net/seminariocsa/article/view/4743/4336>. Acessado em 27.11.2019

Fontenele, R. E. S. (2010). Empreendedorismo, competitividade e crescimento econômico: evidências empíricas. Revista de Administração Contemporânea, v.14,n.6,p.1094-1112. Disponível em: $<$ http://www.scielo.br/pdf/rac/v14n6/v14n6a07.pdf $>$. Acessado em 29.11.2019

Gil, A. (2017). Como elaborar projetos de pesquisa. São Paulo: Altas.173 p

Greco, S. M. S. S. et al. (2010). GEM—Empreendedorismo no Brasil: 2010. Curitiba: IBQP.

Hisrich, R. D.; Peters, M. P.; Shepherd, D. A. (2014). Empreendedorismo. Porto Alegre: Bookman.

Humbert, A. L.; Drew, E. (2010). Gender, entrepreneurship and motivational factors in an Irish context. International Journal of Gender and Entrepreneurship, v.2, n.2, p.173-196. Disponivel em : < http://www.scielo.br/pdf/bbr/v16n3/1808-2386-bbr-16-03-0273.pdf.

Acessado em 05.10.2019

Imaginário, S. S. E. (2017). Criatividade e Empreendedorismo em estudantes: Influência da motivação e das práticas docentes.

Loiola, E. et al. (2016). Ação planejada e intenção empreendedora entre universitários: analisando preditores e mediadores. Revista Psicologia Organizações e Trabalho, v. 16, n. 1, p. 22-35. Disponível em : < http://pepsic.bvsalud.org/pdf/rpot/v16n1/v16n1a03.pdf >.

Acessado em: 26.11.2019

Lopes, R. M. A.; Teixeira, M. A. A. (2010). Educação empreendedora no ensino fundamental. Educação empreendedora: conceitos, modelos e práticas. Rio de Janeiro: Elsevier: São Paulo: SEBRAE..

Marconi, M.; Lakatos. E. (2017). Fundamentos de metodologia cientifica. 8 ed. São Paulo:

Atlas. 346p

Cunha, C. V. M. da; Silva, M. V. da; Yamaguchi, N. M. (2012). Empreendedorismo: histórias que motivam, despertam e encantam. Anuário da Produção Acadêmica Docente, v. 5, n. 12, p. 165-182. Disponível em: < https://repositorio.pgsskroton.com.br/bitstream/123456789/1465/1/Artigo\%2011.pdf $>$. Acessado em: 29.11.2019

Naia, A. M. P. (2009). Importância da formação inicial no empreendedorismo: estudo do percurso empreendedor de licenciados da FMH. Tese de Doutorado.

Neck, H. M.; Greene, P. G. (2011). Entrepreneurship education: known worlds and new frontiers. Journal of small business management, v. 49, n. 1, p. 55-70. Disponível em: $<$ https://pdfs.semanticscholar.org/d86c/f683613f1668c9812d2b7aecfd84e5416c9e.pdf $>$. Acessado em 07.012019

Nunes, G. J. (2015). Formação empreendedora na educação profissional de nível técnico em metalurgia no Instituto Federal de Minas Gerais-Campus Ouro Preto. Aqui eles fizeram história. Faça você a sua., p. 51. Disponível em: $<$

http://www.ideiaeduc.com.br/uploads/revista/pdf/revistas/6N.02 (2015) outubro.mar\%C3\% A7o.pdf $>$. Acessado em: 09.11.2019

Parreira, P. M. et al. (2016). Representações sociais do empreendedorismo: O papel da formação na aquisição de competências empreendedoras. Revista Ibero-Americana de Saúde e Envelhecimento, v. 1, n. 3, p. 266. 
Disponível em: < http://www.revistas.uevora.pt/index.php/saude envelhecimento/article/view/71/122> . Acessado em: 01.11.2019

Pinho, J. C.; Thompson, D. (2016). Condições estruturais empreendedoras na criação de novos negócios: a visão de especialistas. RAE-Revista de Administração de Empresas, v. 56, n. 2, p. 166-181. Disponível em: < https://rae.fgv.br/sites/rae.fgv.br/files/condicoes estruturais empreendedoras na criacao de

novos negocios a visao_de especialistas 0.pdf >. Acessado em: 01.10.2019

Ribas, R. (2011). A motivação empreendedora e as teorias clássicas da motivação. Caderno de Administração. Revista da Faculdade de Administração da FEA, v. 5, n. 1.

Schaefer, R.; Minello, I. F. (2016). Educação Empreendedora: premissas, objetivos e metodologias. Revista Pensamento Contemporâneo em Administração, v. 10, n. 3, p. 60-81. Disponível em: < http://periodicos.uff.br/pca/article/view/11270 >. Acessado em: 01.10.2019

Tavares, C. E.; Moura, G. L. de; Silva, A. (2014). Confrontando atitudes empreendedoras em empreendedores por oportunidade e por necessidade. Conhecimento Interativo, v. 7, n. 1, p. 16-29. Disponível em:

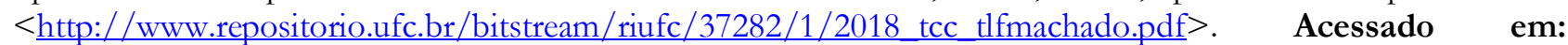
21.11.2019

Vale, G. M. V.; Corrêa, V. S.; Reis, R. F. D. (2014). Motivações para o empreendedorismo: necessidade versus oportunidade?. RAC-Revista de Administração Contemporânea, v. 18, n. 3, p. 311-327. Disponível em: < http://www.scielo.br/pdf/rac/v18n3/v18n3a05.pdf > . Acessado em: 07.10.2019

Vale, G. M. V.; Guimarães, L. de O. (2010). Redes sociais na criação e mortalidade de empresas. RAE-Revista de Administração de Empresas, v.50,n.3,p.325337..Disponívelem:<https://rae.fgv.br/sites/rae.fgv.br/files/artigos/10.1590 75902010000300008.pdf >. Acessado em: 07.10.2019

Valliere, D. (2010). Reconceptualizing entrepreneurial framework conditions. International Entrepreneurship and Management Journal, v. 6, n. 1, p. 97-112. Disponível em: < https://www.researchgate.net/publication/226592202 Reconceptualizing entrepreneurial fra mework conditions $>$. Acessado em: 29.11.2019 